This material has been published in the Elsevier journal Biosensors and Bioelectronics

Full citation: Towards a polymeric binding mimic for cytochrome CYP2D6 Biosensors and Bioelectronics,

Volume 20, Issue 11, 15 May 2005, Pages 2353-2363, Daniel L. Rathbone, Aisha Ali, Polyxeni Antonaki and Sarah Cheek

doi: 10.1016/j.bios. 2005.01.009

Link to journal homepage

http://www.elsevier.com/wps/find/journaldescription.cws_home/405913/description

\title{
Towards a polymeric binding mimic for cytochrome CYP2D6
}

\author{
Daniel L. Rathbone*, Aisha Ali, Polyxeni Antonaki and Sarah Cheek \\ School of Life and Health Sciences, Aston University, Birmingham, B4 7ET, UK \\ ${ }^{*}$ Corresponding author: email D.L.Rathbone@aston.ac.uk; Fax +44 (0)121 3590572.
}

\begin{abstract}
A series of fluorescent molecularly imprinted polymers has been prepared with a view to generating material capable of mimicking the binding characteristics of the metabolically important cytochrome isoform CYP2D6. Such polymers would have the possibility to form the sensing element in a high-throughput assay for the prediction of CYP2D6 affinity. The imprinted polymers possessed binding-dependent fluorescence. They rebound their templates and various cross-reactivities were encountered for test compound/drug recognition. One polymer in particular exhibited a rational discrimination amongst the related synthetic templates and was reasonably successful in recognising CYP2D6 substrates from a drug panel.
\end{abstract}

Keywords: Molecularly imprinted polymer, fluorescence, CYP2D6, binding mimic

\section{Introduction}

\subsection{Cytochromes $P 450$ and CYP2D6}

Mammalian cytochromes P450 are expressed mainly in the liver and constitute a large family of enzymes capable of oxidative metabolism of many endogenous and exogenous compounds. Most drugs are metabolised by this family of enzymes and as a result the half-life of a drug within the body is linked with its rate of cytochrome P450 mediated biotransformation. To complicate matters some P450s are subject to polymorphisms where a significant percentage of any given population either poorly express the enzyme or do not express it at all. Consequently, if the main route of clearance of a group of compounds is through cytochrome P450 metabolism, a proportion of patients that do not express this enzyme normally may be subject to toxicity due to drug accumulation. CYP2D6 is one such problematic enzyme. For example it has been shown to be absent in up to $9 \%$ of the Caucasian population (Eichelbaum et al 1979), an effect which is not observed in Ghanaians 
(Eichelbaum and Woolhouse 1985). Thus it is obvious that the identification of potential CYP2D6 activity amongst libraries of compounds is important in the drug discovery process. Therefore, in this paper, initial work is presented towards the development of a fluorescent molecularly imprinted polymer-based mimic of the binding characteristics of the enzyme CYP2D6.

Human P-450s exist in a lipid microenvironment in the most lipid-rich area of the hepatocyte and consequently crystallisation is difficult. To date Xray crystal structures have only recently been published for CYP2C9 (Williams et al 2003), CYP2B4 (Scott et al 2004) and CYP2C8 (Schoch et al 2004). The crystal coordinates for CYP2D6 are as yet unknown. Through the study of P450cam much has been learned of P-450s' catalytic functions and subsequent studies have revealed that minor structural details such as changes in single amino acid residues on human CYP 2D6 have a significant bearing on its catalytic activity and stereoselectivity (Ellis et al 1996). The known substrates for CYP 2D6 usually have at least one basic nitrogen. The basic nitrogen interacts with the carboxylic acid present in the side chain of Asp301 or Glu216. Distances from the basic nitrogen and a particular site of metabolism appear to be roughly grouped into 5 , 7 and 10 Angstroms. A significant body of molecular modelling work exists wherein the known substrates of CYP 2D6 have been superimposed in a rational manner and used to probe the internal space of the active site. From this knowledge, homology with crystallised bacterial P450s (eg cam, BM3, terp) and the use of NMR spectroscopy upon the enzyme itself, various models of the active site of CYP 2D6 have been proposed and used to predict metabolism of molecules not included in the training set. (Islam et al 1991; Koymans et al 1993; Strobl et al 1993; Modi et al 1996; de Groot et al 1999; Venhorst et al 2003) An advantage of such models is that predictions of CYP 2D6 metabolism may be made without having to synthesise the molecules in question ie virtual libraries may be screened in silico and a subset selected for synthesis on the basis of a favourable conclusion. A possible downside is the difficulty at present in ensuring that a full conformational exploration of a potential substrate is undertaken within the active site model. Indeed, the assumption that only the very lowest energy conformations are allowed for a given potential substrate is a shaky one and may give rise to many false negatives. In contrast, the fluorescent imprinted polymeric binding mimics presented in this paper will allow potential substrates to explore their full conformational potential since actual physical interactions take place.

\subsection{Molecularly imprinted polymers}

Molecularly imprinted polymers (MIPs) are at the heart of the molecular recognition systems presented in this paper. These are crosslinked polymers containing bespoke functionalised cavities arising from the inclusion of template molecules in the polymerisation mixture and their later extraction (Allender at el 1999; Haupt and Mosbach 2000; Alexander et al 2003). When the polymers are prepared functional polymerisable monomers are included which are either temporarily covalently bound to the templates (covalent imprinting) or associate with the templates in the pre-polymerisation mixture (noncovalent imprinting). The functional monomers, once they are part of the polymer matrix, serve to decorate the cavities with functionality appropriate to the template molecules. Overall, binding sites are created which have a memory for the templates both in terms of shape and matching functionality. The process of non-covalent molecular imprinting is shown schematically in Figure 1. 

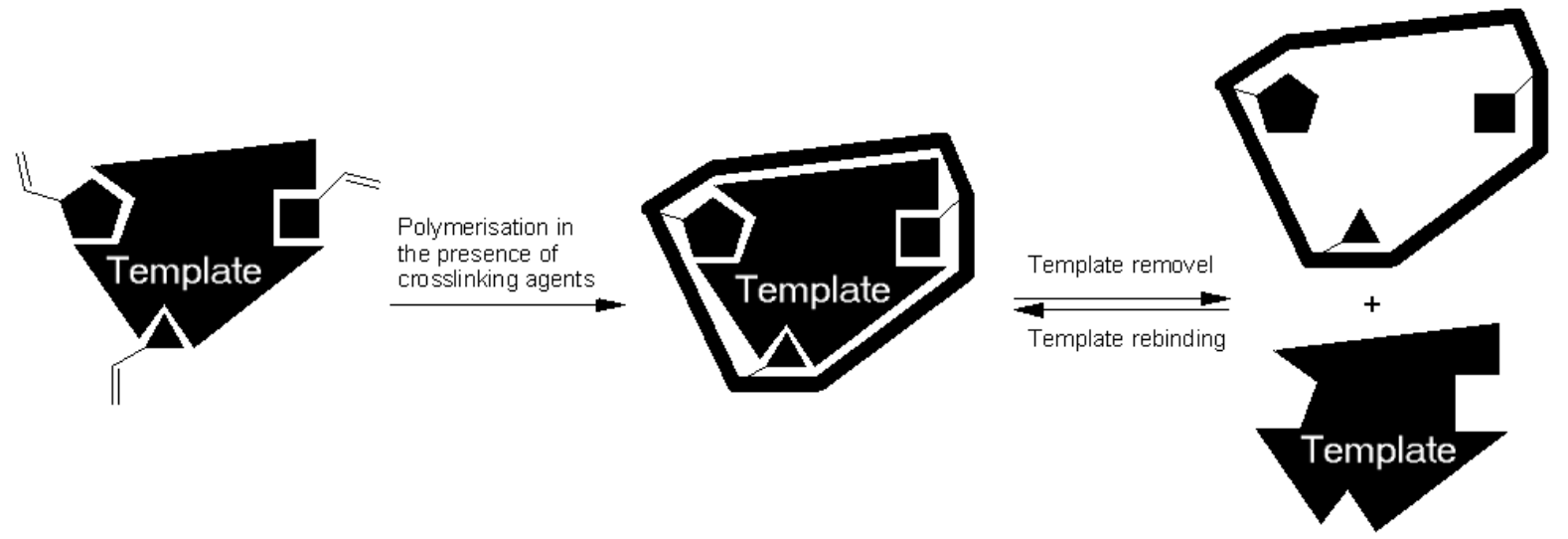

Figure 1 Schematic representation of the process of non-covalent molecular imprinting

Fluorescent molecularly imprinted polymers have the benefit of a fluorophore in their cavities which may respond to the presence of bound test compound by a change in the fluorescence output. Several reports have appeared in the literature wherein imprinted polymers have been prepared which are intrinsically fluorescent. (Turkewitsch et al 1998; Liao et al 1999; Rathbone et al 2000; Rathbone and Ge 2001; Takeuchi et al 2001; Zhang et al 2001; Wandelt et al 2002; Thanh et al 2002; Tong et al 2002). The polymerisable fluorescent functional monomers presented have ranged from simple aromatic arrangements to rather larger porphyrin-based systems. In most cases re-binding of template into the MIP or exposure to appropriate test compounds results in fluorescence quenching in the MIP. Another related approach results in fluorescence enhancement upon substrate binding to the MIP cavities via suppression of a fluorescence quenching mechanism. (Wang et al 1999; Leung et al 2001) There are also reports in which an otherwise non-fluorescent MIP is effectively converted to a fluorescent derivative upon substrate binding. (Liao et et 1999; Subrahmanyam et al $2000 \& 2001$ )

\section{Experimental}

\subsection{Chemicals}

Acryloyl chloride, tetrabutyl ammonium chloride, anthracene-9-carboxahdehyde, $\quad \mathrm{N}, \mathrm{N}$-diispropyl ethylamine, trimethylolpropane triacrylate, octadecylacrylate, magnesium sulphate and potassium hydroxide were purchased from SigmaAldrich. 2-Aminobenzamide, 2(bromomethyl)naphthalene, iminostilbene, styrene and N,N-diphenylhydrazine hydrochloride were purchased from Avocado Research Chemicals Ltd. Pyrene-1-carboxahdehyde was purchased from Lancaster Synthesis. Triethylamine, poly(ethylene glycol) methyl ether (average molecular mass 550) and 2,2'-azobis(2methylpropionitrile) were purchased form Acros Organics. Solvents were purchased from Fisher Chemicals and used as supplied. Thin layer chromatography plates, aluminium-backed silica gel $60 F_{254}$, were obtained from Merck.

\subsection{Instrumentation}

Proton NMR spectra were obtained on a Bruker AC 250 instrument operating at $250 \mathrm{MHz}$ as solutions in $\mathrm{d}_{6}$-DMSO and referenced from $\delta$ DMSO $=2.50 \mathrm{ppm}$ unless otherwise stated. Infrared spectra were recorded as $\mathrm{KBr}$ discs on a Mattson 3000 FTIR spectrophotometer. 
Atmospheric pressure chemical ionisation mass spectrometry (APCl-MS) was carried out on a Hewlett-Packard 5989B quadrupole instrument connected to an electrospray 59987A unit with an APCl accessory and automatic injection using a Hewlett-Packard 1100 series autosampler. Melting points were obtained using a ReichertJung Thermo Galen hot stage microscope and are corrected. Elemental analyses were performed by Butterworth Laboratories Ltd, Teddington UK. Fluorescence measurements were performed in polystyrene [Black Cliniplates from Labsystems, Helsinki, Finland] or polypropylene [Acrowell ${ }^{\mathrm{TM}}$ from Pall Life Sciences] standard format 96-well microtitre plates in a Molecular Devices SpectraMax GeminiXS ${ }^{\mathrm{TM}}$ dual-scanning microtitre plate spectrofluorometer. Structures were drawn, manipulated and optimized using CAChe Worksystem Pro 5.04 (Fujitsu) and display figures were create using WebLab ViewerPro 4.0 (Molecular Simulations Inc).

\subsection{Preparation of the fluorescent monomer,} templates and test compounds

\section{Preparation of 2-acrylamidobenzamide}

Acryloyl chloride $(4.0 \mathrm{~mL}, 44.2 \mathrm{mmol})$ was added dropwise over ten minutes to a solution of $2-$ aminobenzamide $(3.151 \mathrm{~g}, 23.1 \mathrm{mmol})$ and triethylamine $(6.2 \mathrm{~mL}, 44.5 \mathrm{mmol})$ in dry THF $(15 \mathrm{~mL})$. The mixture was stirred at room temperature for $18 \mathrm{~h}$ and then poured onto icewater $(250 \mathrm{~mL})$. The resulting precipitate was collected by filtration, washed with water $(2 \mathrm{x}$ $100 \mathrm{~mL}$ ) and dried under vacuum to give 2acrylamidobenzamide as a pale yellow powder. Yield 1.932g, $10.2 \mathrm{mmol}$, 44\%.

Mp 161.7 - $167.7{ }^{\circ} \mathrm{C}$ (pronounced softening above $\left.135^{\circ} \mathrm{C}\right) ;{ }^{1} \mathrm{H}$ NMR: $5.81(\mathrm{dd}, 1 \mathrm{H}, \mathrm{J}=9.5,2.2$ $\mathrm{Hz}, \mathrm{C}=\mathrm{CH}_{2}$ ), 6.2-6.4 (overlapping $\mathrm{m}, 2 \mathrm{H}, \mathrm{C}=\mathrm{CH}_{2}$ and $\mathrm{COCH}), 7.15(\mathrm{~m}, 1 \mathrm{H}, \mathrm{Ar}-4 \mathrm{H}), 7.49(\mathrm{~m}, 1 \mathrm{H}, \mathrm{Ar}-$ $5 \mathrm{H}$ ), 7.76 (bs, $1 \mathrm{H}, \mathrm{NH}_{2}$ ), 7.83 (dd, $1 \mathrm{H}, \mathrm{J}=1.3,7.9$ $\mathrm{Hz}, \mathrm{Ar}-3 \mathrm{H}), 8.30$ (bs, 1H, $\left.\mathrm{NH}_{2}\right), 8.53(\mathrm{~d}, 1 \mathrm{H}, \mathrm{J}=$
7.6Hz, Ar-6H ), 12.01 (bs, 1H, CONH) ppm; MS (+ APCI): $191(\mathrm{M}+\mathrm{H})^{+}, 174\left(\mathrm{M}-\mathrm{NH}_{2}\right)^{+} ; \mathrm{IR} v=3361$, 3191, 1675 (CO), 1628, 1583, 1525, 1448, 1396 $\mathrm{cm}^{-1}$

Preparation of a linear copolymer of octadecylacrylate and 2-acrylamidobenzamide

A solution of 2-acrylamidobenzamide (5.3 mg, $0.027 \mathrm{mmol}$ ), AIBN (54 mg) and octadecylacrylate (4.956 g, $15.5 \mathrm{mmol})$ in THF (15 mL) was deoxygenated by alternate application of vacuum and argon $(5 \mathrm{x})$ with rapid stirring. The solution was stirred at $70{ }^{\circ} \mathrm{C}$ for $18 \mathrm{~h}$ under an argon atmosphere. The solution was poured onto rapidly stirred methanol $(250 \mathrm{~mL})$. The resulting precipitate was collected by filtration, re-dissolved in a small amount of dichloromethane and reprecipitated onto methanol. The precipitate was collected by filtration and dried under vacuum to give a white powder. Yield 4.30g, 86\%.

Preparation of 5-Naphthalen-2-ylmethyl-5Hdibenzo[b,f]azepine 1

A biphasic mixture of aqueous potassium hydroxide $(6 \mathrm{M}, 50 \mathrm{~mL})$, toluene $(15 \mathrm{~mL})$, iminostilbene (2.372 g, $12.3 \mathrm{mmol}), \quad$ 2(bromomethyl)naphthalene (1.862g, $8.42 \mathrm{mmol})$ and tetrabutyl ammonium chloride $(0.185 \mathrm{~g}, 0.67$ mmol) was stirred at room temperature for 10 days and then at $76{ }^{\circ} \mathrm{C}$ for 1 day. The mixture was partitioned between water $(100 \mathrm{~mL})$ and ethyl acetate $(100 \mathrm{~mL})$. The organic layer was dried over magnesium sulphate and evaporated to give the crude product. The compound was purified by flash chromatography eluting with dichloromethane and petroleum ether $1 / 4$ rising to 1/1. The fractions corresponding to $\operatorname{Rf} 0.63$ were combined and the solvent was evaporated to give the target compound as a pale yellow crystalline solid. The target compound was further recrytallised in hot ethanol. Yield 1.915g, 5.73 $\mathrm{mmol}, 68 \%$. 
Mp 119.4 - $120.6{ }^{\circ} \mathrm{C} ;{ }^{1} \mathrm{H}$ NMR: 5.11 (s, $2 \mathrm{H}, \mathrm{CH}_{2}$ ), 6.87 (s, 2H, ArC트=C븟), 6.90-6.97 (overlapping $\mathrm{m}, 2 \mathrm{H}, \operatorname{Ar}-\mathrm{H}), 7.11(\mathrm{~d}, 2 \mathrm{H}, \mathrm{J}=7.2 \mathrm{~Hz}, \operatorname{Ar}-\mathrm{H}), 7.20-$ 7.24 (overlapping $\mathrm{m}, \quad 4 \mathrm{H}, \quad \mathrm{Ar}-\mathrm{H}$ ), $\quad$ 7.38-7.48 ((overlapping $\mathrm{m}, 2 \mathrm{H}, \mathrm{Ar}-\mathrm{H}), 7.59$ (dd, $1 \mathrm{H}, \mathrm{J}=0.4$, 8.7Hz, Naphthyl-H), 7.74 (d, $1 \mathrm{H}, \quad J=8.7 \mathrm{~Hz}$, naphthyl-H), 7.76-7.82 (overlapping $\mathrm{m}, 2 \mathrm{H}, \mathrm{Ar}-\mathrm{H}$ ), 7.91 (s, 1H, naphthyl-H) ppm; MS (+APCl) $\mathrm{m} / \mathrm{z}=$ $334(\mathrm{M}+\mathrm{H})^{+}$; IR $(\mathrm{KBr}) v=3047,3018,2819,1595$, 1569, 1483, 1456, 1432, 1348, $1215 \mathrm{~cm}^{-1}$. Elemental analysis: Found \% (calculated \%), C 90.03 (90.06), H 5.76 (5.74), N 4.20 (4.20).

Preparation of $\quad N^{\prime}$-[1-anthracen-9-yl-meth-(E)ylidene]- $N, N$-diphenylhydrazine 2

A mixture of $\mathrm{N}, \mathrm{N}$-diphenylhydrazine hydrochloride (2.084 g, $9.4 \mathrm{mmol}$ ), anthracene-9carboxahdehyde $(2.157 \mathrm{~g}, 10.5 \mathrm{mmol})$ and $\mathrm{N}, \mathrm{N}-$ diispropyl ethylamine $(3.5 \mathrm{~mL}, 20.3 \mathrm{mmol})$ in ethanol $(20 \mathrm{~mL})$ was stirred at reflux for 2 days. The mixture was cooled to room temperature and the crude product was collected by filtration and recrystallised from ethanol to give the title compound as a dull yellow crystalline solid. Yield $2.990 \mathrm{~g}, 8.04 \mathrm{mmol}, 86 \%$.

Single component as judged by TLC (Ethyl acetate - petroleum spirit $\left[40-60^{\circ} \mathrm{C}\right.$ boiling range] 3/7) RF 0.88. Mp 194.6 - $195.5{ }^{\circ} \mathrm{C}$. ${ }^{1} \mathrm{H}$ NMR: 7.25-7.35 (overlapping $\mathrm{m}, 6 \mathrm{H}, \mathrm{Ar}-\mathrm{H}$ ), 7.49-7.61 (overlapping $\mathrm{m}, 8 \mathrm{H}, \mathrm{Ar}-\mathrm{H}$ ), 8.07-8.13 (overlapping $\mathrm{m}, 2 \mathrm{H}, \operatorname{Ar}-\mathrm{H}), 8.14(\mathrm{~s}, 1 \mathrm{H}, \mathrm{N}=\mathrm{CH}), 8.34-8.41$ (overlapping $\mathrm{m}, 2 \mathrm{H}, \mathrm{Ar}-\mathrm{H}), 8.60(\mathrm{~s}, 1 \mathrm{H}$, anthryl$\mathrm{H} 10) \mathrm{ppm}$. MS (+APCl) $\mathrm{m} / \mathrm{z}=373(\mathrm{M}+\mathrm{H})^{+} ; \mathrm{IR} v=$ 3053, 3025, 1587, 1494, 1448, 1323, 1304, 1207 $\mathrm{cm}^{-1}$. Elemental analysis: Found \% (calculated \%) C 86.92 (87.07), H 5.38 (5.41), N 7.41 (7.52).

Preparation of N'-[1-pyren-9-yl-meth-(E)-ylidene]$\mathrm{N}, \mathrm{N}$-diphenylhydrazine 3

A mixture of $\mathrm{N}, \mathrm{N}$-diphenylhydrazine hydrochloride (2.051 g, $9.3 \mathrm{mmol}$ ), pyrene-1-carboxahdehyde $(2.387 \mathrm{~g}, \quad 10.5 \mathrm{mmol})$ and $\mathrm{N}, \mathrm{N}$-diispropyl ethylamine $(3.5 \mathrm{~mL}, 20.3 \mathrm{mmol})$ in ethanol $(20$ $\mathrm{mL}$ ) was stirred at reflux for 2 days. The mixture was cooled to room temperature and the crude product was collected by filtration and recrystallised from ethanol to give the title compound as a brown crystalline solid. Yield $1.277 \mathrm{~g}, 3.2 \mathrm{mmol}, 35 \%$.

Mp 125.2 - $127.0{ }^{\circ} \mathrm{C} ;{ }^{1} \mathrm{H}$ NMR: 7.28-7.37 (overlapping $\mathrm{m}, 6 \mathrm{H}, \mathrm{Ar}-\mathrm{H}$ ), 7.57 (t, $4 \mathrm{H}, \mathrm{J}=8.4 \mathrm{~Hz}$, Ar-H), $8.07(1 \mathrm{H}, \mathrm{t}, \mathrm{J}=7.7 \mathrm{~Hz}$, pyrenyl-H), $8.12(\mathrm{~s}$, $1 \mathrm{H}, \mathrm{N}=\mathrm{CH}), 8.18(\mathrm{~s}, 2 \mathrm{H}, \operatorname{Ar}-\mathrm{H}), 8.23(\mathrm{~d}, 2 \mathrm{H}$, $\mathrm{J}=8.3 \mathrm{~Hz}, \mathrm{Ar}-\mathrm{H}$ ), 8.27-8.34 (overlapping $\mathrm{m}, 3 \mathrm{H}, \mathrm{Ar}-$ $\mathrm{H}), 8.61(\mathrm{~d}, 1 \mathrm{H}, \mathrm{J}=8.3 \mathrm{~Hz}$, pyrenyl-H) ppm; MS $(+\mathrm{APCl}) \mathrm{m} / \mathrm{z}=396(\mathrm{M}+), 168\left(\mathrm{M}-\mathrm{Ph}_{2} \mathrm{~N}\right)^{+} ; \mathrm{IR}(\mathrm{KBr})$ $v=1593,1577,1558,1483,1384,1278,1207$ $\mathrm{cm}^{-1}$. Elemental analysis: Found \% (calculated \%) C 87.57 (87.85), H 5.06 (5.08), N 6.82 (7.07).

Preparation of N'-[1-phenanthracen-9-yl-meth-(E)ylidene]-N,N-diphenylhydrazine 4

A mixture of $\mathrm{N}, \mathrm{N}$-diphenylhydrazine hydrochloride (2.047 g, $9.3 \mathrm{mmol}$ ), anthracene-9carboxahdehyde (2.096 g, $10.2 \mathrm{mmol}$ ) and N,Ndiispropyl ethylamine $(3.5 \mathrm{~mL}, 20.3 \mathrm{mmol})$ in ethanol $(20 \mathrm{~mL})$ was stirred at reflux for 2 days. The mixture was cooled to room temperature and the crude product was collected by filtration and recrystallised from ethanol to give the title compound as a khaki crystalline solid. Yield $1.20 \mathrm{~g}, 3.2 \mathrm{mmol}$, 35\%. Single component as judged by TLC (Ethyl acetate - petroleum spirit [40-60 ${ }^{\circ} \mathrm{C}$ boiling range] 3/7) RF 0.70. Mp $118.5-$ $122.5{ }^{\circ} \mathrm{C} ;{ }^{1} \mathrm{H} \quad \mathrm{NMR}\left(\mathrm{CDCl}_{3} ; \delta \mathrm{CDCl}_{3}=7.27 \mathrm{ppm}\right)$ 7.23-7.36 (overlapping $\mathrm{m}, 6 \mathrm{H}, \mathrm{Ar}-\mathrm{H}$ ), 7.46-7.72 (overlapping $\mathrm{m}, \quad 8 \mathrm{H}, \quad \mathrm{Ar}-\mathrm{H}$ ), $7.87 \quad(\mathrm{~s}, \quad 1 \mathrm{H}$, phenanthrenyl-H), 7.91 (m, $1 \mathrm{H}$, phenanthrenyl-H), $8.06(\mathrm{~s}, 1 \mathrm{H}, \mathrm{N}=\mathrm{CH}$ ), 8.63-8.78 (overlapping $\mathrm{m}$, $3 \mathrm{H}, \mathrm{Ar}-\mathrm{H}) \mathrm{ppm} ; \mathrm{MS}(+\mathrm{APCl}) \mathrm{m} / \mathrm{z}=373(\mathrm{M}+\mathrm{H})^{+}$, $168\left(\mathrm{M}-\mathrm{Ph}_{2} \mathrm{~N}\right)^{+} ; \mathrm{IR}(\mathrm{KBr}) v=3056,3031,1585$, 1564, 1495, 1452, 1386, $1296 \mathrm{~cm}^{-1}$. Elemental analysis: Found \% (calculated \%) C 86.97 (87.07), 5.38 (5.41), N 7.42 (7.52). 


\subsection{General procedure for the preparation of imprinted polymers}

A solution of 2-acrylamidobenzamide $(4.8 \mathrm{mg}$, $0.025 \mathrm{mmol}$ or twice this amount), the template ( $0.025 \mathrm{mmol}$ or twice this amount), AIBN (50 mg) and the crosslinker $(5.0 \mathrm{~g})$ in THF $(5 \mathrm{~mL})$ was deoxygenated by alternate application of vacuum and argon $(5 x)$ with rapid stirring. The solution was stirred at $55^{\circ} \mathrm{C}$ for $24 \mathrm{~h}$ and then at $70^{\circ} \mathrm{C}$ for a further $24 \mathrm{~h}$ under an argon atmosphere. The resulting polymer was collected by filtration and washed with THF $(2 \times 30 \mathrm{~mL})$. The crude material was dried under vacuum and then crushed using a mortar and pestle. The powder was graded by sieving and the 150-382 $\mu \mathrm{m}$ fraction was extracted exhaustively with chloroform in a soxhlet apparatus and dried under vacuum.

\subsection{Fluorescence studies on MIPs after extraction of template and after re- exposure to template or exposure to test compounds}

The imprinted polymer $(0.05 \mathrm{~g})$ was shaken with the test solution $(0.1,1.0$ and $5.0 \mathrm{mg} / \mathrm{mL}$ in THF) for 1 day, collected by filtration, washed very briefly with THF $(5 \mathrm{~mL})$ dried under vacuum. The resulting powders were weighed accurately (about $5 \mathrm{mg}$ per well) in triplicate into black polystyrene 96 well plates. A layer of polyethyleneglycol $(0.2$ $\mathrm{mL}$ ) was added to each well and the MIPs were examined by fluorescence ( $\left.\lambda_{\text {ex }} 309 \mathrm{~nm}\right)$.

2.6. Fluorescence studies on thin films of cooctadecylacrylate-2-acrylamidobenzamide in the presence of test compounds

A stock solution of the co-polymer was prepared in chloroform at a concentration of $46.2 \mathrm{mg} / \mathrm{mL}$. Solutions of the test compounds in THF were prepared at a concentration of $1 \mathrm{mg} / \mathrm{mL}$. Aliquots of the co-polymer solution $(0.1 \mathrm{~mL})$ were applied to the wells of a polypropylene 96 well plate resulting in a polymer content of $4.6 \mathrm{mg}$ per well. The same wells were also treated in triplicate with aliquots of the test compounds $(0.02,0.05$ or 0.1 $\mathrm{mL}$ ) giving test compound contents of 0.02, 0.05 or $0.1 \mathrm{mg}$ per well. Some wells were left with copolymer solution only. The solvent was allowed to evaporate and the plate was further dried by careful application of vacuum over an 18 hour period to give polymer film deposits on the base of the wells. The fluorescence of the films was investigated at the same excitation wavelength used for the MIP studies, 309nm.

\subsection{Molecular modeling}

A structure coordinate file containing superimposed CYP2D6 substrates (Islam et al, 1991) was modified to leave the more rigid molecules (dextromethorphan, codeine, sparteine (2 orientations), debrisoquine, desipramine and amitriptyline) but removing smaller and the more flexible compounds. The template molecules 1, 2 and $\mathbf{3}$ were drawn using CAChe Worksystem Pro. The rotatable bonds were identified and a conformational search was undertaken using the CONFLEX module. The resulting lowest energy conformations suggested by this process were subjected to semi-empirical geometry optimisation (keywords PM3 GEO-OK GNORM=0.1) (Stewart 1989). The templates 1, 2 and $\mathbf{3}$ were separately superimposed upon desipramine in the reduced CYP2D6 substrates structure file. The basic nitrogen of each template was superimposed upon either the ring nitrogen or the exocyclic nitrogen of desipramine whilst attempting to attain maximum ring overlap.

\section{Results and discussion}

\subsection{Template design and synthesis}

In order for embark upon the molecular imprinting studies a suitable template was required. The 
crystal structure of CYP2D6 is as yet unknown but in lieu of this a series of relatively rigid templates, potentially representing the "negative" of the active site and containing at least one basic nitrogen, was designed based upon a rational summation of the superimposed known enzyme substrates. Islam et al (1991) in generating an in silico model for human CYP2D6 have previously superimposed the metabolised atoms of a series of CYP2D6 substrates onto the attacked C5 atom of camphor from the X-ray structure of P450cam. They arranged matters such that the substrates did not have marked steric clashes with haem and also so that the potential basic (protonated) nitrogen could interact with a proposed anion location and all the aromatic rings containing attacked atoms lay approximately coplanar. The coordinate file of the superimposed CYP2D6 substrates was kindly provided by the said authors. In order to make the superimposed substrates more amenable to template design the very conformationally flexible substrates were deleted from the superimposed structure file to leave a set comprising relatively rigid compounds; dextromethorphan, codeine, sparteine (2 orientations), debrisoquine, desipramine and amitriptyline. A set of compounds related to desipramine (Figure 2, 1-3), when superimposed upon desipramine in the original set, were found to encompass a significant portion of the union volume and to present a range of basic nitrogens. The pared down superimposed substrates structure set is shown in Figure 3 with desipramine and codeine highlighted and also compounds 1-3 superimposed on desipramine. Codeine was also chosen as a template since it is a large and virtually rigid member of the known CYP2D6 substrate set (Goshman et al, 1999). It was thought that its rigidity would enhance the possibility of a good imprinting effect.

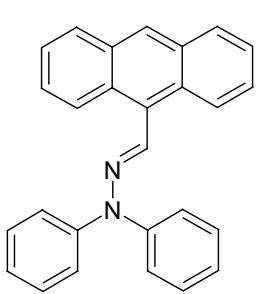

2<smiles>C(=N/N(c1ccccc1)c1ccccc1)\c1ccc2ccc3cccc4ccc1c2c34</smiles>

3<smiles>C(=N/N(c1ccccc1)c1ccccc1)\c1cc2ccccc2c2ccccc12</smiles>

4

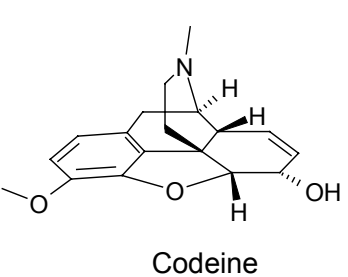

Codeine<smiles>CNCCC=C1c2ccccc2CCc2ccccc21</smiles><smiles>CN(C)CC/C=C1/c2ccccc2COc2ccccc21</smiles>

Doxepin<smiles>CN(C)CCCN1c2ccccc2Sc2ccc(Cl)cc21</smiles>

Chlorpromazine

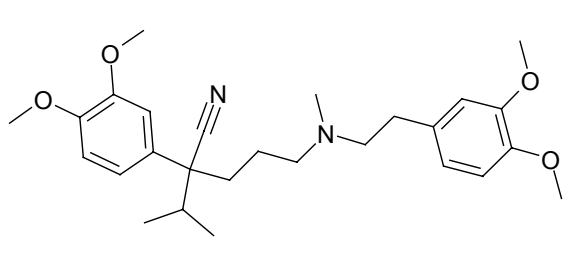

Verapamil<smiles>CC(C)Cc1ccc(C(C)C(=O)O)cc1</smiles>

Ibuprofen

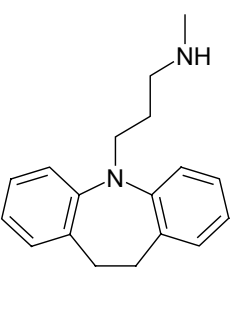

Desipramine

Figure 2 The structures of the fluorescent monomer, templates and test compounds used in the study. Desipramine was not used but is referred to in the discussion. 


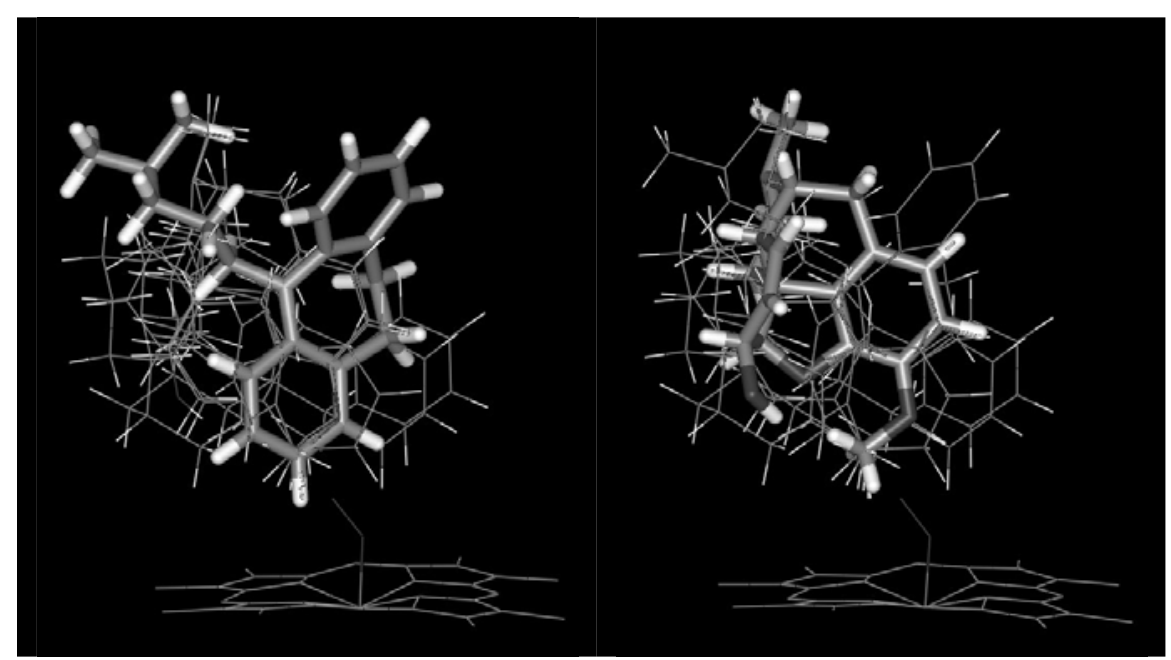

(a)

(b)

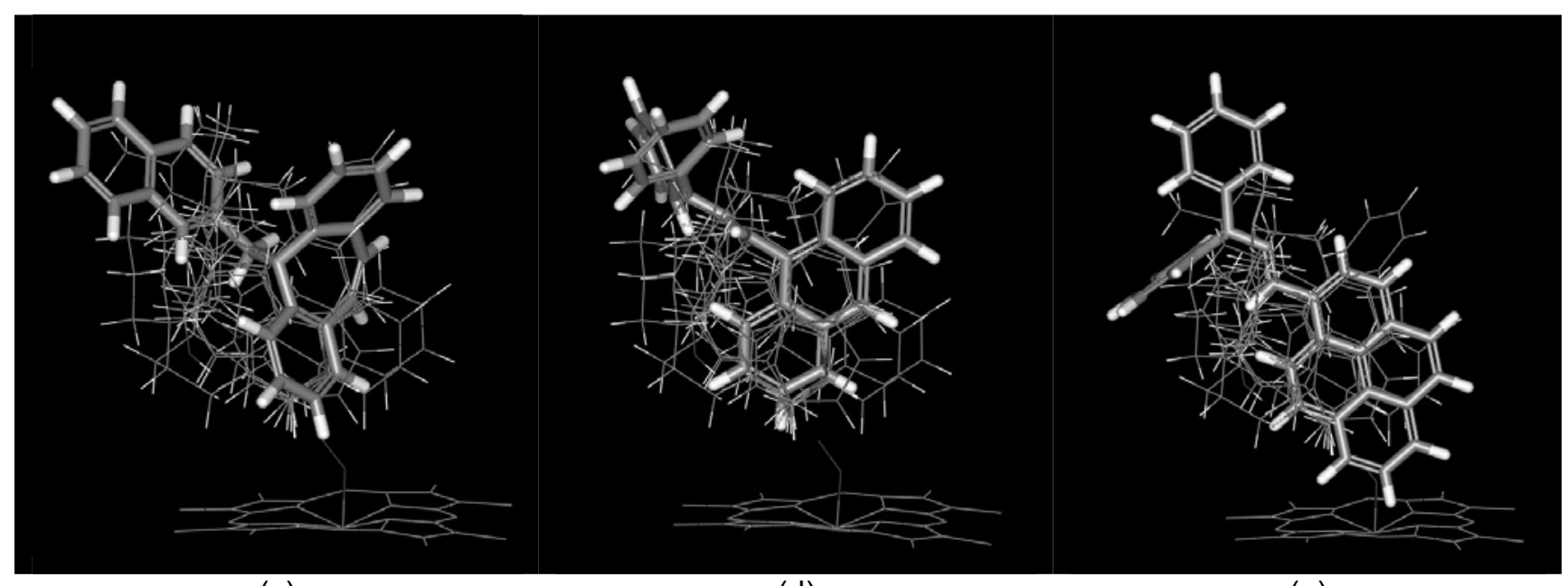

(c)

(d)

(e)

Figure 3 Reduced set of superimposed CYP2D6 substrates (Islam et al, 1991) with the haem unit shown for reference.

(a) Desipramine highlighted; (b) Codeine highlighted; (c) 1 superimposed on desipramine; (d) 2 superimposed on desipramine; (e) 3 superimposed on desipramine

3.2. Preparation of templates, test compounds and fluorescent monomer

The first template 1, containing the naphthylmethylene group, was prepared by alkylation of iminostilbene under biphasic conditions and assisted by phase transfer catalysis. This is a variation of a previously published procedure employed to benzylate iminostilbene (Gozlan et al 1982). Templates 2 and 3 and test compound 4 were prepared by
Schiff-base formation between N,Ndiphenylhydrazine and the corresponding aldehydes. The fluorescent monomer, 2acrylamidobenzamide, was chosen since it has three hydrogen bond donors capable of interacting with the acceptor nitrogen present in the templates. It was prepared by acylation of 2-aminobenzamide with acryloyl chloride. 
3.3. Preparation of imprinted polymers and exposure to templates and test compounds

A series of MIPs was constructed wherein the compound 2-acrylamidonenzamide (Figure 2) was used both as a functional monomer and a fluorophore such that the MIP cavities would exhibit binding-dependant fluorescence. Compounds 1-3 and codeine were employed as templates. In the cases of templates 1 and 2 an initial series of six polymers each were prepared where the monomer:template $(\mathrm{M}: \mathrm{T})$ ratio was varied 1:2, 1:1 and 2:1 and the crosslinking agent was ethyleneglycol dimethacrylate (EGDMA) or trimethylolpropane triacrylate (TMPTA). The MIPs were pulverised, graded by sieving and the template was extracted using a soxhlet apparatus. These "empty" MIPs were re-exposed to solutions of their templates $(0.1,1.0$ and $5.0 \mathrm{mg} / \mathrm{mL})$ collected by filtration, dried and examined by fluorescence. The optimum excitation wavelength, as determined from the empty polymers, was $309 \mathrm{~nm}$. Maximum fluorescence emission was observed at $460 \mathrm{~nm}$. Each of the MIPs suffered dose-dependent fluorescence quenching after rebinding of its template. An example is shown in Figure 4.

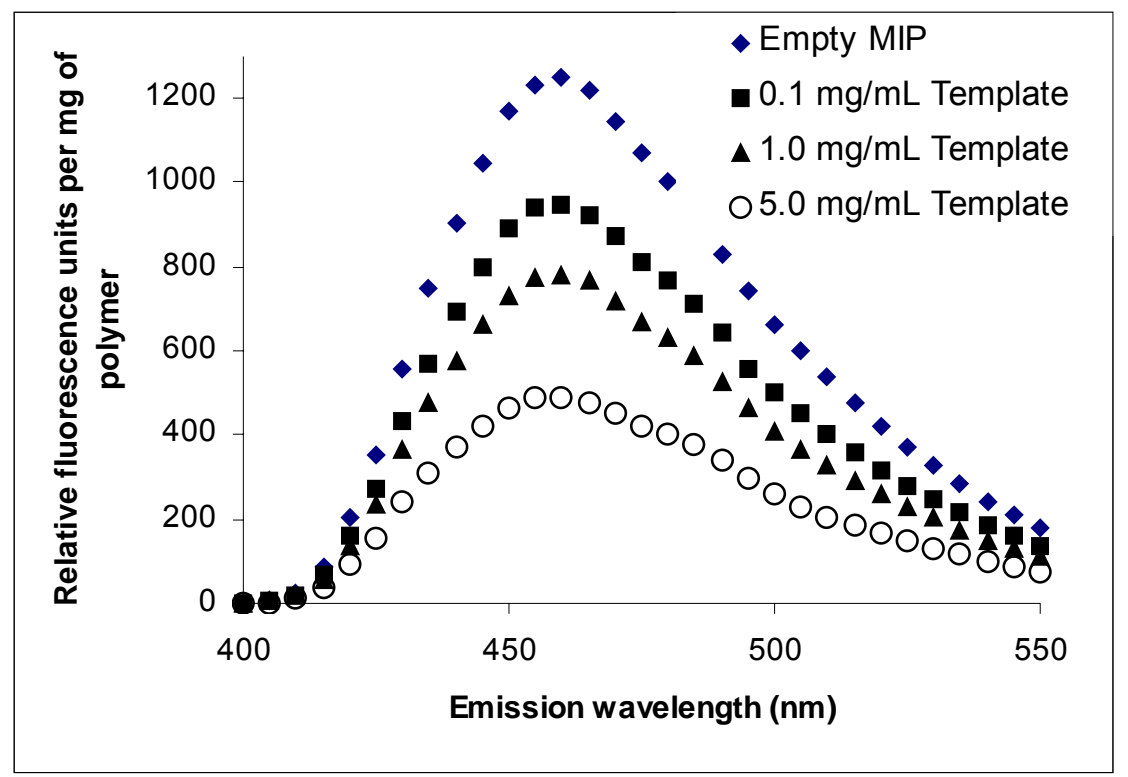

Figure 4: Dose-dependent fluorescence spectra for MIP1 re-exposed to solutions of its template $\left(\lambda_{\mathrm{ex}}=309 \mathrm{~nm}\right)$

The results for the $5 \mathrm{mg} / \mathrm{mL}$ exposures are given in Table 1. For template 1 the best quenching was observed for a M:T ratio of 2:1 and TMPTA as crossinker ("MIP1"). For template 2 the best result was with M:T 1:1 and EGDMA ("MIP2"). These combinations were carried forward into the synthesis of new MIPs in an attempt to establish the optimum crosslinker content. 
Fluorescence relative to the empty MIPs after re-exposure to template at a concentration of $5 \mathrm{mg} / \mathrm{mL}$

\begin{tabular}{lccccccc} 
& Crosslinker & TMPTA & TMPTA & TMPTA & EGDMA & EGDMA & EGDMA \\
& M:T & $1: 1$ & $1: 2$ & $2: 1$ & $1: 1$ & $1: 2$ & $2: 1$ \\
\hline Template 1 & & 0.65 & 0.74 & 0.27 & 0.72 & 0.65 & 0.74 \\
& & $( \pm 0.05)^{*}$ & $( \pm 0.14)$ & $( \pm 0.05)$ & $( \pm 0.13)$ & $( \pm 0.12)$ & $( \pm 0.04)$ \\
Template 2 & & 0.46 & 0.34 & 0.52 & 0.27 & 0.31 & 0.46 \\
& & $( \pm 0.06)$ & $( \pm 0.00)$ & $( \pm 0.05)$ & $( \pm 0.07)$ & $( \pm 0.04)$ & $( \pm 0.15)$ \\
\hline
\end{tabular}

${ }^{*}$ Standard deviations for triplicate results are given parentheses.

Table 1 Fluorescence relative to the empty MIPs after re-exposure to template at $5 \mathrm{mg} / \mathrm{mL}$

Thus, new MIPs were prepared where the crosslinkers were diluted with styrene to give crosslinker contents of $95,90,85$ and $80 \% \mathrm{w} / \mathrm{w}$. The MIPs were processed and exposed to their templates as before and the fluorescence quenching results are shown in Table 2. It can be seen that for MIPs templated with 1 there was no improvement in template recognition upon dilution of the crosslinker as judged by the extent of fluorescence quenching. Indeed, at 95\% crosslinking the fluorescence quenching was significantly worse and thereafter recovered slightly at the lower crosslinker contents. For MIPs derived from template 2 a similar trend was observed. After the decline in quenching at $95 \%$ crosslinker the figures at $85 \%$ and $80 \%$ returned, within experimental error, to the quenching observed for $100 \%$ crosslinking. Overall, for templates $\mathbf{1}$ and 2, there was no advantage in reducing the crosslinker content.

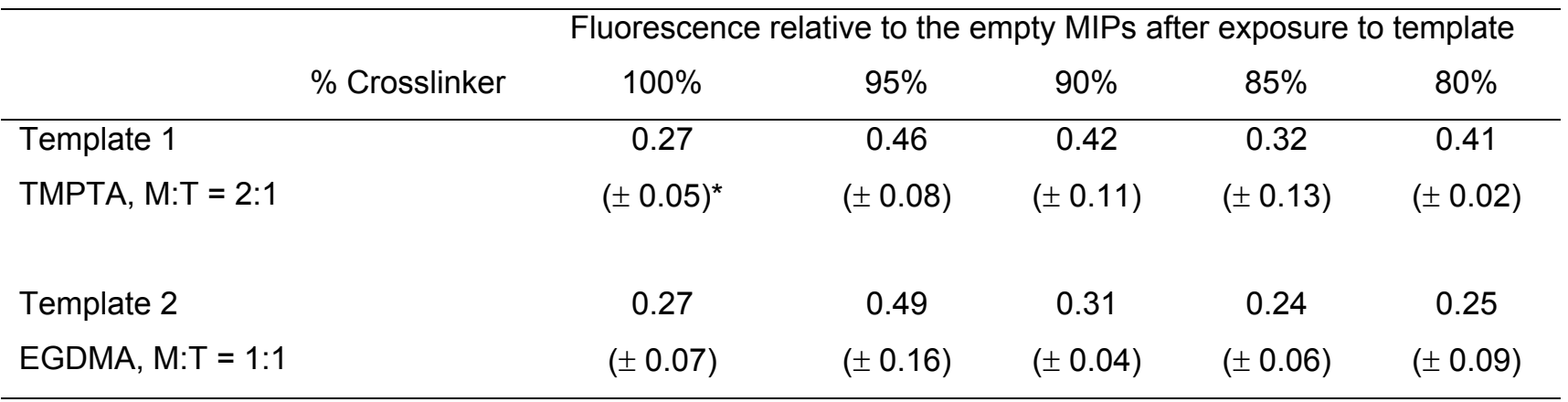

*Standard deviations for triplicate results are given parentheses.

Table 2 Fluorescence relative to the empty MIPs with reduced crosslinker content after re-exposure to template. The $100 \%$ crosslinker result is included for comparison.

A further two MIPs were prepared with 3 and codeine as templates but using triethyleneglycol dimethacrylate (TEGDMA) as the crosslinker (giving "MIP3" and "MIPcod" respectively). The change to a longer and more flexible crosslinker was occasioned by our observation that use of $100 \%$ TMPTA or EGDMA made it difficult to achieve adequate extraction from monolithic polymers of templates containing rigid motifs the size of pyrene or greater. All four MIPs were challenged with solutions of templates and test compounds in THF at concentrations of 0.1, 1.0 and $5.0 \mathrm{mg} / \mathrm{mL}$. The structures of the test compounds are shown in Figure 2 and include the CYP2D6 substrates nortriptyline (Venkatakrishnan et al, 1999), doxepin (Kirchheiner et al, 2002), 
codeine (Ereshefsky et al , 1995), the CYP2D6 inhibitor chlorpromazine (Shin et al 1999), the CYP3A4 substrate verapamil (Wang et al, 2004), and the CYP2C9 substrate ibuprofen (Hamman et al, 1997)

After isolation of the polymers and thorough drying under vacuum their fluorescence was recorded. Again, dose-dependent fluorescence quenching was observed. The effects were most marked at the highest test solution concentration, $5 \mathrm{mg} / \mathrm{mL}$ and it is these results which are presented in Table 3, normalised to the fluorescence output per unit mass of the empty MIPs.

\begin{tabular}{ccccc}
\hline Test compound & MIP1 & MIP2 & MIP3 & MIPcod \\
\hline $\mathbf{1}$ & $0.27( \pm 0.05)$ & $0.54( \pm 0.04)$ & $0.59( \pm 0.05)$ & $0.79( \pm 0.12)$ \\
$\mathbf{2}$ & $0.49( \pm 0.10)$ & $0.27( \pm 0.06)$ & $0.20( \pm 0.06)$ & $0.66( \pm 0.04)$ \\
$\mathbf{3}$ & $0.61( \pm 0.01)$ & $0.95( \pm 0.21)$ & $0.07( \pm 0.02)$ & $0.60( \pm 0.07)$ \\
$\mathbf{4}$ & $0.72( \pm 0.05)$ & $1.03( \pm 0.22)$ & $0.20( \pm 0.03)$ & $0.90( \pm 0.25)$ \\
Nortriptyline & $0.89( \pm 0.13)$ & $0.24( \pm 0.08)$ & $0.45( \pm 0.14)$ & $0.92( \pm 0.25)$ \\
Doxepin & $1.15( \pm 0.23)$ & $0.25( \pm 0.05)$ & $0.38( \pm 0.06)$ & $1.08( \pm 0.25)$ \\
Chlorpromazine & $1.08( \pm 0.22)$ & $0.54( \pm 0.08)$ & $0.38( \pm 0.06)$ & $0.55( \pm 0.13)$ \\
Verapamil & $1.30( \pm 0.19)$ & $0.95( \pm 0.51)$ & $0.67( \pm 0.13)$ & $0.83( \pm 0.23)$ \\
Ibuprofen & $1.34( \pm 0.15)$ & $0.35( \pm 0.08)$ & $0.65( \pm 0.12)$ & $0.99( \pm 0.10)$ \\
Codeine & $1.24( \pm 0.05)$ & $0.76( \pm 0.23)$ & $0.74( \pm 0.11)$ & $0.86( \pm 0.02)$ \\
\hline
\end{tabular}

Table 3 Fluorescence output of imprinted polymers after exposure to test compound solutions at a concentration of $5 \mathrm{mg} / \mathrm{mL}$. The results are normalised to the fluorescence of the unquenched MIP and the quoted errors are the standard deviations of triplicate wells. $\lambda_{\mathrm{ex}}=309 \mathrm{~nm}, \lambda_{\mathrm{em}}=460 \mathrm{~nm}$.

Taken at face value the following trends can be discerned in the fluorescence quenching results. MIP1 and MIP3 represent two extremes. MIP1 recognised its own template and compounds 2-4 but discriminated against all the test drugs. On the other hand MIP3 showed no selectivity at all since its fluorescence was quenched by its template and all the other test compounds. MIPcod recognised the four templates and chlorpromazine. MIP2 recognised its template (2), rejected the related compounds $\mathbf{3}$ and $\mathbf{4}$ as well as verapamil but recognised $\mathbf{1}$, nortriptyline, doxepin, chlorpromazine, ibuprofen and codeine.

\subsection{Preparation of a soluble copolymer of} octadecylacrylate and 2-acrylamidobenzamide and fluorescence quenching in deposited thin films

The interpretation of fluorescence quenching results remains problematic. If fluorescence quenching has occurred then the test compound must have entered the MIP cavity. If there is no quenching or the quenching is weak, then the result is potentially ambiguous if the quenching ability of the test compound towards the fluorophore is unknown. As an aid to the interpretation of any MIP fluorescence quenching encountered a soluble polymer containing the fluorophore was prepared by the copolymerisation of octadecylacrylate and the 
fluorescent monomer. Solutions of this polymer together with the templates and test compounds were evaporated in flat-bottomed microtitre plate wells. Careful application of vacuum resulted smooth dry films being deposited on the well floors. In our hands this has proved to be a more reliable approach than simply evaporation of a solution containing the fluorophore and a test compound which usually resulted in a non-uniform deposition on the well floor with consequently highly variable fluorescence readings. Therefore the polymer film approach was followed and the fluorescence of the films was determined. This allowed the relative florescence quenching abilities of the templates and test compounds in a polymeric environment to be discerned which in turn was used to inform the evaluation of the MIP results. The fluorescence of the polymer films at the wavelength combination used to examine the imprinted polymers $(309 / 460 \mathrm{~nm})$ is presented in Figure 5 normalised to that of the polymer film without test compound.

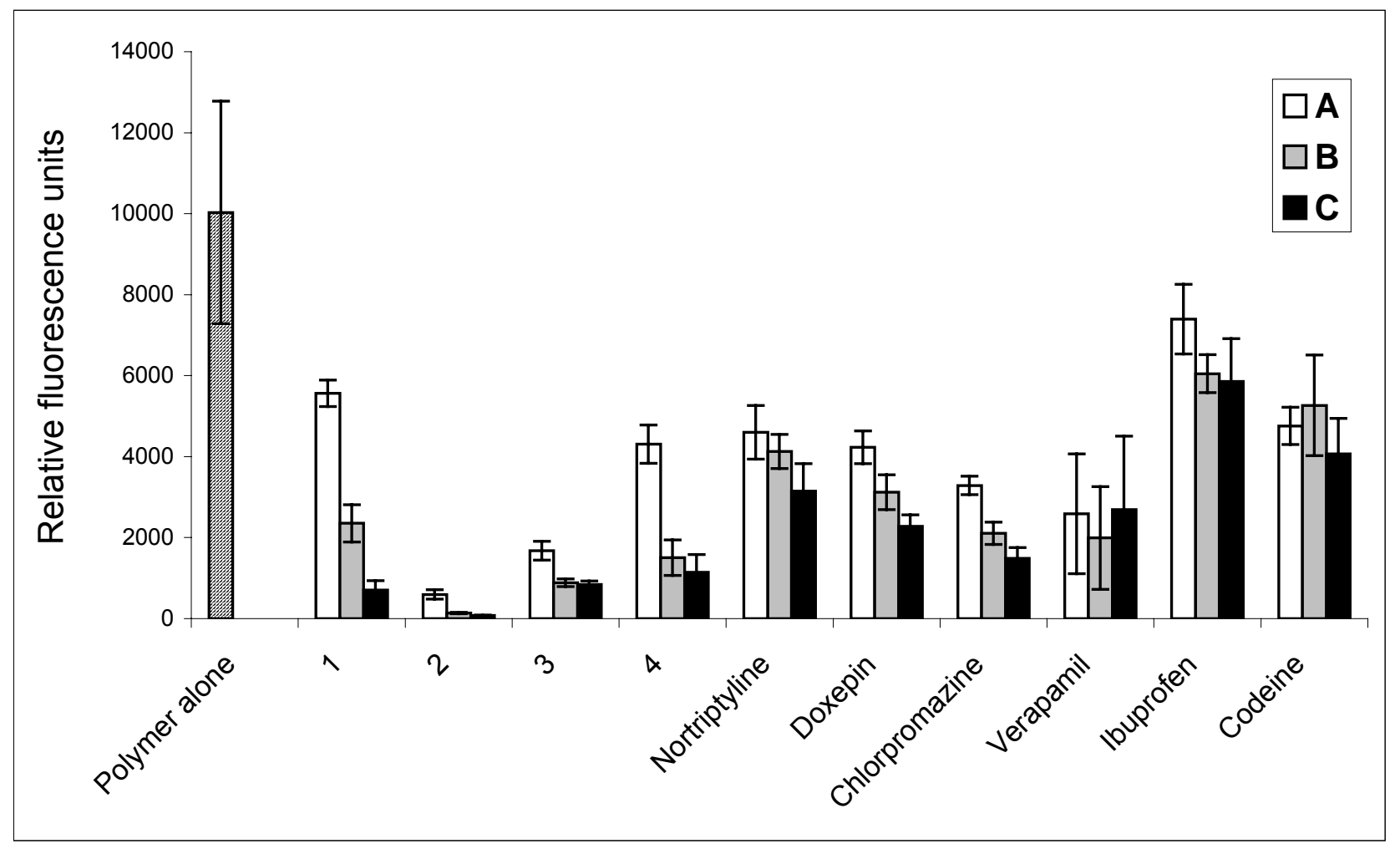

Figure 5 Fluorescence output of a co-octadecylacrylate-2-acrylamidobenzamide film (4.6 mg per well) after co-evaporation of solutions of test compounds (A, 0.02; B, 0.05; C, $0.1 \mathrm{mg}$ per well). The fluorescence of the unquenched polymer film is shown at the left hand side. The quoted errors are the standard deviations of triplicate wells. $\lambda_{\mathrm{ex}}=309 \mathrm{~nm}, \lambda_{\mathrm{em}}=460 \mathrm{~nm}$.

All of the test compounds caused fluorescence quenching to various extents at the emission maximum of the polymer film $(460 \mathrm{~nm})$. The polycyclic aromatic compounds 1-4, which were the best fluorescence quenching agents of the polymer film, also exhibited low level broad featureless emission at longer wavelengths as can be seen in Figure 6. Taking these observations into account the test compounds were given a relative quenching rating of good, moderate or poor (Table 4). 


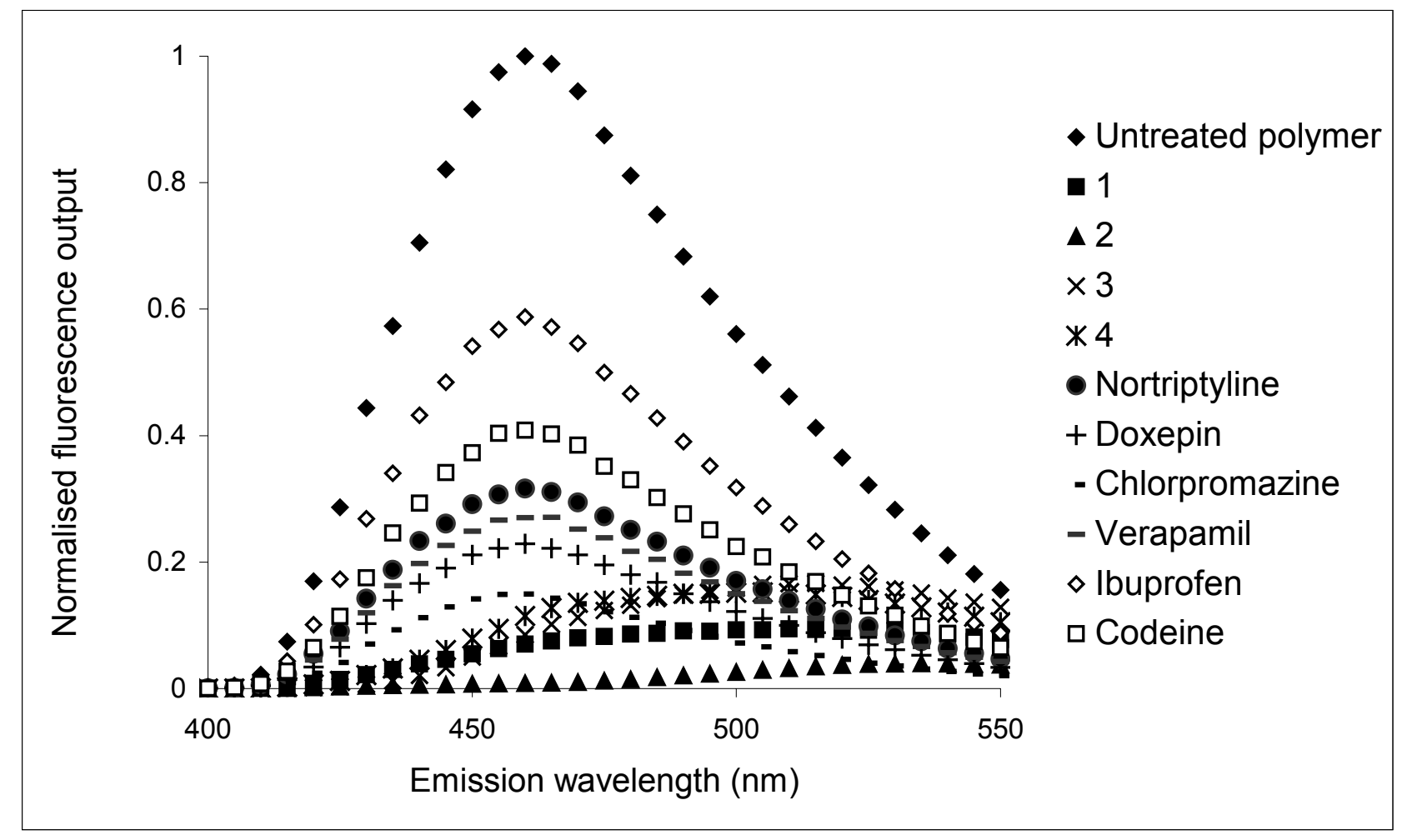

Figure 6 Fluorescence spectra $\left(\lambda_{\mathrm{ex}}=309 \mathrm{~nm}\right)$ of a co-octadecylacrylate-2-acrylamidobenzamide film (4.6 $\mathrm{mg}$ per well) after co-evaporation of solutions of test compounds ( $0.1 \mathrm{mg}$ per well). The emission curves are normalised to that of the untreated polymer and result from the average of three wells.

\begin{tabular}{clccccc}
\hline Test substance & & $\begin{array}{c}\text { Fluorescence } \\
\text { quenching ability }\end{array}$ & MIP1 & MIP2 & MIP3 & MIPcod \\
\hline 1 & & Good & + & + & + & - \\
2 & Good & + & + & + & + \\
3 & Good & + & - & + & + \\
4 & Good & + & - & + & - \\
Nortriptyline & CYP2D6 substrate & Moderate & - & + & + & - \\
Doxepin & CYP2D6 substrate & Moderate & - & + & + & - \\
Chlorpromazine & CYP2D6 inhibitor & Moderate & - & + & + & + \\
Verapamil & CYP3A4 substrate & Moderate & - & - & + & + \\
Ibuprofen & CYP2C9 substrate & Poor & - & + & + & - \\
Codeine & CYP2D6 substrate & Poor & - & + & + & + \\
\hline
\end{tabular}

Table 4 Interpretation of the MIP fluorescence quenching observations

+ Test substance recognised by the MIP

- Test substance not recognised by the MIP 


\subsection{Interpretation of the MIP fluorescence} quenching observations

It should be noted that each test compound had caused fluorescence quenching in at least one of the MIPs. This, taken together with the thin film quenching results, enabled a reassessment of the MIP cross-reactivity profiles which is presented in Table 4. It was observed that in some cases where the test compound was judged to be a poor quencher, that moderate to good quenching could still be observed inside a MIP (for example ibuprofen with MIP2). This would suggest there to be a difference in orientation between the test compound and the fluorophore in the MIP compared with the non-imprinted polymer film.

For MIP1 the interpretation remained unchanged on the raw data. This MIP, whilst able to recognise compounds 1-4, was unable to accept the drug test compounds. MIP2 recognised compound 1 in addition to its template (2) but was able to discriminate against the closely related compounds $\mathbf{3}$ and $\mathbf{4}$. Of the four MIPs this polymer appears to be the most promising as a starting point for further progress towards a binding mimic for CYP2D6. Having exhibited an imprinting effect with regard to compounds 1-4, it accepted the CYP2D6 substrates / inhibitors nortriptyline, doxepine, chlorpromazine and codeine but rejected the CYP3A4 substrate verapamil. Ibuprofen, however, a CYP2C9 substrate, was accepted. MIP3 remained indiscriminate in its acceptance of the test compounds. This is perhaps not surprising since its template (3) contained the largest substituent of the set, namely a pyrene moiety. MIPcod exhibited an interesting discrimination in that it accepted compounds 2 and 3 but rejected 1 and 4 . This is surprising since 4 is two methylene units smaller than $\mathbf{3}$ and can be directly superimposed upon $\mathbf{3}$. A judgement of rejection of compound $\mathbf{1}$ in this case was decided upon because, although slight quenching was observed $\quad(0.79 \pm 0.12$ fluorescence relative to the empty MIP), 1 had been shown to be a good quencher. In contrast, recognition of template (codeine, $0.86 \pm 0.02$ fluorescence relative to the empty MIP) was allowed since codeine was shown to be a relatively poor quencher. Thus, MIPcod recognised half of the test drugs but was not specific to CYP2D6 substrates. Considering the templates used it would appear that $\mathbf{1}$ is too small, $\mathbf{2}$ is approximately the correct size, $\mathbf{3}$ is too large and codeine has the wrong profile.

\section{Conclusions}

A series of imprinted polymers has been prepared with a view to generating material capable of mimicking the binding characteristics of the metabolically important cytochrome isoform CYP 2D6. The imprinted polymers re-bound their templates and various cross-reactivities were encountered for test compound/drug recognition. MIP2 in particular exhibited a rational discrimination amongst the related synthetic templates and was reasonably successful in recognising CYP2D6 substrates from the drug set. MIP2 and its template (compound 2) are the subject of ongoing optimisation studies to broaden the scope of these results and make further progress towards a binding mimic of CYP2D6.

\section{Acknowledgements}

This work was funded by a research grant from the EPSRC UK.

\section{References}

Alexander, C., Davidson, L., Hayes, W., 2003. Imprinted polymers: artificial molecular recognition materials with applications in synthesis and catalysis. Tetrahedron. 59, 2025-2057. 
Allender, C. J., Brain K. R., Heard C. M., 1999.

Molecularly Imprinted Polymers - Preparation,

Biomedical Applications and Technical

Challenges. Progress in Med. Chem. 36, 235-291. de Groot, M.J., Ackland, M.J., Horne, V.A., Alex, A.A., Jones, B.C., 1999. Novel approach to predicting $\mathrm{P} 450$-mediated drug metabolism: development of a combined protein and pharmacophore model for CYP2D6. J. Med. Chem. 42(9), 1515-1524.

Eichelbaum, M., Woolhouse, N.M., 1985. Interethnic difference in sparteine oxidation among Ghanaians and Germans. Eur. J. Clin. Pharmacol. 28(1), 79-83.

Eichelbaum, M., Spannbrucker, N., Steincke, B., Dengler, H.J., 1979. Defective N-oxidation of sparteine in man: a new pharmacogenetic defect.

Eu.r J. Clin. Pharmacol., 16(3),183-7

Ellis, S.W., Rowland, K., Ackland, M.J., Rekka, E., Simula, A.P., Lennard, M.S., Wolf, C.R., Tucker, G.T., 1996. Influence of amino acid residue 374 of cytochrome P-450 2D6 (CYP2D6) on the regioand enantio-selective metabolism of metoprolol. Biochem J. 316(2), 647-54.

Ereshefsky, L., Riesenman, C., Lam, Y.W., 1995, Antidepressant drug interactions and the cytochrome P450 system. The role of cytochrome P450 2D6. Clin. Pharmacokinet. 29 Suppl 1:10-8; discussion 18-9.

Goshman, L., Fish, J., Roller, K., 1999. Clinically Significant Cytochrome P450 Drug Interactions. Journal of the Pharmacy Society of Wisconsin. May/June, 23-38.

Gozlan, I., Halpern, M., Rabinovitz, M., Avnir, D., Ladkani, D., 1982. Phase-transfer catalysis in nalkylations of the pharmaceutical intermediates 5h-dibenz[b,f]azepine and 5h-10,11dihydrodibenz[b,f]azepine. J. Heterocyclic Chem., 19 (6), 1569-1571

Hamman, M.A., Thompson, G.A., Hall, S.D., 1997. Regioselective and Stereoselective
Metabolism of Ibuprofen by Human Cytochrome P450 2C. Biochemical Pharmacology. 54, 33-41. Haupt, K., Mosbach, K., 2000. Molecularly Imprinted Polymers and Their Use in Biomimetic Sensors. Chem. Rev. 100, 2495-2504.

Islam, S.A., Wolf, C.R., Lennard, M.S., Sternberg, M.J.E., 1991. A three-dimensional molecular template for substrates of human cytochrome P450 involved in debrisoquine 4-hydroxylation. Carcinogenesis 12, 2211-2219

Kirchheiner, J., Meineke, I., Muller, G., Roots, I., Brockmoller, J., 2002. Contributions of CYP2D6, CYP2C9 and CYP2C19 to the biotransformation of $\mathrm{E}$ - and Z-doxepin in healthy volunteers. Pharmacogenetics. 12(7), 571-80.

Koymans, L.M., Vermeulen, N.P., Baarslag, A., Donne-Op den Kelder, G.M., 1993. A preliminary 3D model for cytochrome P450 2D6 constructed by homology model building.

J. Comput. Aided Mol Des. 7(3), 281-289.

Liao, Y., Wang, W., Wang, B.H., 1999. Building fluorescent sensors by template polymerization: The preparation of a fluorescent sensor for $\mathrm{L}$ tryptophan. Bioorganic Chemistry 27(6), 463-476. Leung, M.K.P., Chow, C.F., Lam, M.H.W., 2001. A sol-gel derived molecular imprinted luminescent PET sensing material for 2,4dichlorophenoxyacetic acid. Journal of Materials Chemistry 11(12), 2985-2991.

Modi, S., Paine, M.J., Sutcliffe, M.J., Lian, L.Y., Primrose, W.U., Wol,f C.R., Roberts, G.C., 1996. A model for human cytochrome P450 2D6 based on homology modeling and NMR studies of substrate binding. Biochemistry 35(14), 45404550.

Rathbone, D.L., Su, D., Wang, Y., Billington, D.C., 2000. Molecular recognition by fluorescent imprinted polymers. Tetrahedron Letters 41(1), 123-126.

Rathbone, D.L., Ge, Y., 2001. Selectivity of response in fluorescent polymers imprinted with 
$N^{1}$-benzylidene pyridine-2-carboxamidrazones. Analytica Chimica Acta 435(1) 129-136.

Schoch, G.A., Yano, J.K., Wester, M.R., Griffin, K.J., Stout, C.D., Johnson, E.F., 2004. Structure of human microsomal cytochrome P4502C8 Evidence for a peripheral fatty acid binding site. J. Biol. Chem. 279(10), 9497-9503

Scott, E.E., White, M.A., He, Y.A., Johnson, E.F., Stout, C.D., Halpert, J.R., 2004. Structure of Mammalian Cytochrome P450 2B4 Complexed With 4-(4-Chlorophenyl)Imidazole at 1.9- $\AA$ Resolution. Insight Into the Range of P450 Conformations and the Coordination of Redox Partner Binding. J. Biol. Chem., 279(26), 2729427301.

Shin, J-G., Soukhova, N., Flockhart, D.A., 1999. Effect of Antipsychotic Drugs on Human Liver Cytochrome P-450 (Суp) Isoforms In Vitro: Preferential Inhibition Of CYP2D6. Drug Metabolism And Disposition. 27(9), 1078-1084. Strobl, G.R., von Kruedener, S., Stockigt, J., Guengerich, F.P., Wolf,f T., 1993. Development of a pharmacophore for inhibition of human liver cytochrome P-450 2D6: molecular modelling and inhibition studies. J. Med. Chem. 36(9), 11361145.

Subrahmanyam, S., Piletsky, S.A., Piletska, E.V., Chen, B.N., Day, R., Turner, A.P.F., 2000. "Biteand-switch" approach to creatine recognition by use of molecularly imprinted polymers. Advanced Materials 12:722-724.

Subrahmanyam, S., Piletsky, S.A., Piletska, E.V., Chen, B.N., Karim, K., Turner, A.P.F., 2001. 'Biteand-Switch' approach using computationally designed molecularly imprinted polymers for sensing of creatinine. Biosensors \& Bioelectronics 16(9-12), 631-637.

Takeuchi, T., Mukawa, T., Matsu, J., Higashi, M., Shimizu, K.D., 2001. Molecularly imprinted polymers with metalloporphyrin-based molecular recognition sites coassembled with methacrylic acid. Analytical Chemistry 73(16), 3869-3874.

Thanh, N.T.K., Rathbone, D.L., Billington, D.C., Hartell, N.A., 2002. Selective Recognition Of Cyclic GMP Using A Fluorescence-Based Molecularly Imprinted Polymer. Analytical Letters 35(15), 2499-2509.

Tong, A.J., Dong, H., Li, H.D., 2002. Molecular imprinting-based fluorescent chemosensor for histamine using zinc (II)-protoporphyrin as a functional monomer. Analytica Chimica Acta 466(1), 31-37.

Turkewitsch, .P, Wandelt, B., Darling, G.D., Powell, W.S., 1998. Fluorescent functional recognition sites through molecular imprinting. A polymer-based fluorescent chemosensor for aqueous CAMP. Analytical Chemistry 70(10), 2025-2030.

Venhorst, J., ter Laak, A.M., Commandeur, J.N., Funae, Y., Hiroi, T., Vermeulen, N.P., 2003. Homology modeling of rat and human cytochrome P450 2D (CYP2D) isoforms and computational rationalization of experimental ligand-binding specificities. J. Med. Chem. 46(1), 74-86.

Venkatakrishnan, K., von Moltke, L.L., Greenblatt, D.J., 1999. Nortriptyline E-10-Hydroxylation in Vitro Is Mediated by Human CYP2D6 (High Affinity) and CYP3A4 (Low Affinity): Implications for Interactions with Enzyme-Inducing Drugs. J. Clin. Pharmacol. 39, 567-577

Wandelt, B., Turkewitsch, P., Wysocki, S., Darling, G.D., 2002. Fluorescent molecularly imprinted polymer studied by time-resolved fluorescence spectroscopy. Polymer 43(9), 27772785.

Wang, Y-H., Jones, D.R., Hall, S.D., 2004. Prediction of Cytochrome P450 3A Inhibition by Verapamil Enantiomers and Their Metabolites. Drug Metabolism And Disposition 32, 259-266.

Wang, W., Gao, S.H., Wang, B.H., 1999. Building fluorescent sensors by template polymerization: 
The preparation of a fluorescent sensor for D-

Fructose. Organic Letters 1(8), 1209-1212.

Williams, P.A., Cosme, J., Ward ,A., Angova,

H.C., Vinkovic, D.M., Jhoti, H., 2003. Crystal

structure of human cytochrome P4502C9 with

bound warfarin. Nature 424, 464-468

Zhang, H., Verboom, W., Reinhoudt, D.N., 2001.

9-(Guanidinomethyl)-10-vinylanthracene: a

suitable fluorescent monomer for MIPs.

Tetrahedron Letters 42(26), 4413-4416. 